\title{
The Portfolio and Risk analysis of Pension fund in China based on the market-oriented operation
}

\author{
Xuan Meng ${ }^{1, a}$, Xianglian Zhao ${ }^{2, b}$ \\ ${ }^{12}$ College of Economic and Management, Nanjing University of Aeronautics and Astronautics, \\ Nanjing 210000, China; \\ amengxuan1203@163.com, ${ }^{\mathrm{b}}$ njxlzhao@126.com
}

Keywords: Pension fund; Portfolio; Risk analysis.

\begin{abstract}
The pension fund investment operations in China are in a critical period of marketization and diversified investment. This article uses the bank deposit, treasury bond, stock as the investment tools and combines the theory of portfolio to build the portfolio model of pension fund. Under the income situation of maintaining value, slightly value-added, appreciation, we analyze the investment risk and put forward the countermeasures to reduce risk, and gives suggestions for perfecting the investment model of pension fund.
\end{abstract}

\section{Introduction}

The pension fund is a major social security, which involves people's livelihood. Based on the past policies, investment ways are limited to bank deposit and national debt. The yield is lower than the national consumer price (CPI), which is in a state of devaluation. Founded by Markowitz in the 1950s, the modern portfolio theory makes contributions to the quantitative risk analysis. William Sharp and Stephen Ross achieved further development [1]. David Neumark considered the advantages of age discrimination on social security reform, while Alisdair McKay[3]thought social security privatization is more beneficial to the improvement of the efficiency. In our country, Xiang Huaicheng [4] put forward that pension payment faces trouble and the investment efficiency was low. Since then, many scholars started their research on this issue. Li Yong [5] thought that investing to the stock market was a feasible way to improve the operational efficiency of investment; Tang Dapeng [6] got further study and proposed that the portfolio could effectively reduce the investment risk; Gu Mingshu [7] had done lots of work on broadening the investment channels and evaluating all kinds of investment risks on the basis of the optimal investment strategy. Nowadays, the national policies are relaxing pension investment channels, which makes it necessary to do the research on investment of pension funds based on the market-oriented operation both on theoretical and realistic aspects, and makes it meaningful to realize social steady and harmonious development[8].

\section{The portfolio of pension fund}

\subsection{The choice of investment tool}

In order to simplify the process, the article selects the bank deposit, treasury bond, stock as investment tools [9]. We usually choose bank deposit of 1 year as the main investment vehicle. As shown in table 1 . On the selection of yields in the stock market, we use accumulative turnover of Shanghai stock market and Shenzhen stock market as weight to determine comprehensive index based on the data of Shanghai composite index and Shenzhen component index. In addition, the article selects the growth rates per month of Shanghai bond index as treasury month yield.

Table 1 Cumulative turnover of two major stock exchange markets

\begin{tabular}{ccccc}
\hline Market & From & To & Cumulative turnover (trillion) & weight \\
\hline Shanghai stock exchange & $1991-4$ & $2014-12-31$ & 243.17 & 0.57 \\
Shenzhen stock exchange & $1991-4$ & $2014-12-31$ & 182.90 & 0.43 \\
\hline
\end{tabular}

Data sources: The Shanghai stock exchange, Shenzhen stock exchange's official website 


\subsection{The correlation analysis of return and risk of investment tools}

Table 2 Different assets status of return and risk (monthly interest rate)

\begin{tabular}{ccccccc}
\hline Items & $\mathrm{N}$ & Minimum & Maximum & Average & $\begin{array}{c}\text { Standard } \\
\text { deviation }\end{array}$ & Variance \\
\hline Comprehensive & 60 & -0.089081204 & 0.208646594 & 0.00661162268 & 0.066700327704 & 0.004 \\
The debt index & 60 & -0.002778304 & 0.008178760 & 0.00266068342 & 0.001765027604 & 0.000 \\
Bank deposit & 60 & 0.000167000 & 0.000417000 & 0.00031941667 & 0.000059291378 & 0.000 \\
\hline
\end{tabular}

Data sources: Calculation form months yields (2010-2014)

Contrast returns-risk of different assets (table 2), yields of stock market are greater than treasury bonds and bank deposit interest rate, which are $0.66 \%, 0.27 \%$ and $0.03 \%$ respectively. But the yield range of stock market is bigger than the yield of treasury bond and bank deposit. It contradicts and the basic investment principle of pension fund, the security.

Table 3 Relevant information different assets

\begin{tabular}{ccccc}
\hline & & Comprehensive & The debt index & Bank deposit \\
\hline Comprehensive & Pearson correlation & 1 & -0.054 & -0.067 \\
& Significant (both sides) & - & 0.680 & 0.610 \\
The debt index & N & 60 & 60 & 60 \\
& Pearson correlation & -0.054 & 1 & 0.105 \\
& Significant (both sides) & 0.680 & - & 0.423 \\
Bank deposit & N & 60 & 60 & 60 \\
& Pearson correlation & -0.067 & 0.105 & 1 \\
& Significant (both sides) & 0.610 & 0.423 & - \\
& N & 60 & 60 & 60 \\
\hline
\end{tabular}

The article analyzes comprehensive monthly returns, the two major markets index monthly returns on debt and bank deposits on yield of our country by using SPSS19.0. The correlation coefficient between the deposit interest rate and bond yield $r=0.105$; The correlation coefficient between bank deposit and stock yield $r=0.067$; The correlation coefficient between the treasury bond and stock yield is $r=0.054$. Bank deposit has the lowest correlation with stock, while it has the highest correlation with the treasury bond[10].

\subsection{The determination of target yield}

Considering the investment objectives of pension fund, the target yield is divided into three conditions: (1) Maintaining value. Safety is the primary purpose of pension fund investment, therefore, its investment return shall not be less than the consumer price level (CPI) in the process of actual investment. (2) Slightly value-added. To ensure the basic purchasing power of the pension fund, the investment rate shall not be less than urban residents disposable income growth across the country. (3) Appreciation. The ultimate goal of pension fund investment is to realize the value of the fund. Therefore, the pension fund should enjoy the dividends of high-speed economic development, while its investment yield should synchronize with economic development. In this article, we use gross domestic product (GDP) to determine the highest investment objectives.

\section{The portfolio construction of pension fund}

(1) The construction of portfolio returns-risk model

This article assumes that the overall yield of pension fund portfolio is $p . K_{1}, K_{2}, K_{3}$ represent stock, treasury bond and bank deposit respectively. And the proportion of investment is $w_{1}, w_{2}, w_{3}, w_{1}+w_{2}+w_{3}=1$. Assuming that $r_{i}$ was the expected yield of $K_{i}, i=1,2,3$.So the expected yield of the portfolio $P$ is:

$E\left(r_{p}\right)=\sum_{i=1}^{n} w_{i} E\left(r_{i}\right)=w_{1} E\left(r_{1}\right)+w_{2} E\left(r_{2}\right)+\left(1-w_{1}-w_{2}\right) E\left(r_{3}\right)$

We can reach the point that the variance of the portfolio $\mathrm{P}$ is: 
$\sigma_{p}^{2}=\sum_{i=1}^{n} \sum_{j=1}^{n} w_{i} w_{j} \sigma_{i} \sigma_{j} \rho_{i j}=w_{1}^{2} \sigma_{1}^{2}+w_{2}^{2} \sigma_{2}^{2}+w_{3}^{2} \sigma_{3}^{2}+\rho_{12} w_{1} w_{2} \sigma_{1}^{2} \sigma_{2}^{2}+\rho_{13} w_{1} w_{3} \sigma_{1}^{2} \sigma_{3}^{2}+\rho_{23} w_{2} w_{3} \sigma_{2}^{2} \sigma_{3}^{2}$

(2) Use CPI monthly growth rate as expected yield

This article selects 2008-2014 CPI monthly growth. After calculation, the CPI average annual growth rate is $2.57 \%$, and the average monthly growth rate is $0.214286 \%$. Due to $E\left(r_{1}\right)=0.006611623$ $E\left(r_{2}\right)=0.002660683 \quad E\left(r_{3}\right)=0.000319417 \quad \sigma_{1}^{2}=0.004448934 \quad \sigma_{2}^{2}=0.000003115 \quad \sigma_{3}^{2}=0.000000004 \quad \rho_{12}=-0.054$ $\rho_{13}=-0.067 \quad \rho_{23}=0.105$ We can draw: $0.00214286=w_{1} \times 0.006611623+w_{2} \times 0.002660683+\left(1-w_{1}-w_{2}\right) \times 0.000319417$

Based on the lagrange multiplier method:

$L\left(w_{1}, w_{2}, \lambda\right)=w_{1}^{2} \times 0.004448934+w_{2}^{2} \times 0.000003115+\left(1-w_{1}-w_{2}\right)^{2} \times 0.000000004-0.054 \times w_{1} w_{2} \times 0.000000014$ $-0.067 \times w_{1} \times\left(1-w_{1}-w_{2}\right) \times 0.0000000000156+0.105 \times w_{2} \times\left(1-w_{1}-w_{2}\right) \times 0.000000000000011$

$+\lambda \times\left(w_{1} \times 0.006611623+w_{2} \times 0.002660683+\left(1-w_{1}-w_{2}\right) 0.000319417-0.00214286\right)$

Then we take the derivative, when the formula equals 0 :

$w_{1}=0.0293, w_{2}=0.0927, w_{3}=1-0.0293-0.0927=0.878$ and $\sigma^{2}=0.000000564$.

(3) Use national urban residents disposable income growth as the target yield

This article selects the annual urban residents disposable income growth from 2008 to 2014.By calculating, the annual growth rate is $8.26 \%$, average monthly growth rate is $0.688095 \%$.Due to $E(C P I)=0.00688095$ We can infer: $w_{1}=0.2013, w_{2}=0.4214, w_{3}=1-0.2013-0.4214=0.3773$ So, if makes the guarantee fund of primary endowment insurance is slightly surplus, the proportions of investing are $20.13 \%, 42.14 \%, 37.73 \%$,respectively. And $\sigma^{2}=0.0000664$.

(4) Use GDP growth rate as expected yield

The average annual GDP growth rate is $8.59 \%$, the average monthly growth rate is $0.72 \%$. Due to $E(C P I)=0.0072$, we can calculate the proportion of investing is $24.3 \%, 47.8 \%, 27.9 \%$, respectively. And $\sigma^{2}=0.0001262$.

\section{Risk analysis of pension fund portfolio}

The diversified operation of China's pension fund investment operation faces various risks, such as policy risk, purchasing power risk, credit risk and interest rate risk and so on. We should be prudent in risk analysis within the safe scope of the pension fund investment.

\subsection{Establish the range of the risk}

Table 4 Pension fund investment risk analysis

\begin{tabular}{ccc}
\hline Signal & Condition & Range \\
\hline Green & Safe & $\sigma^{2} \leq 0.000000004$ \\
Light blue & Basic security & $0.000000004 \leq \sigma^{2} \leq 0.000000564$ \\
Yellow & Low risk & $0.000000564 \leq \sigma^{2} \leq 0.0000664$ \\
Double yellow & Moderate risk & $0.0000664 \leq \sigma^{2} \leq 0.0001262$ \\
Red & High risk & $0.0001262 \leq \sigma^{2} \leq 0.004448934$ \\
Double red & Crisis risk & $0.004448934 \leq \sigma^{2}$ \\
\hline
\end{tabular}




\subsection{The handling of the investment risk of pension fund}

Table 5 Different allocation of stock, treasury debt, bank deposit

\begin{tabular}{cccccc}
\hline $\begin{array}{c}\text { Stock } \\
\mathrm{w}_{1}\end{array}$ & $\begin{array}{c}\text { Treasury debt } \\
\mathrm{w}_{2}\end{array}$ & $\begin{array}{c}\text { Bank } \\
\text { deposit } \mathrm{w}_{3}\end{array}$ & $\begin{array}{c}\text { Average } \\
\text { monthly yield }\end{array}$ & Variance & $\begin{array}{c}\text { Standard } \\
\text { deviation }\end{array}$ \\
\hline $0 \%$ & $10 \%$ & $90 \%$ & 0.000553543 & 0.000000315 & 0.000229865 \\
$5 \%$ & $10 \%$ & $85 \%$ & 0.000868154 & 0.000222761 & 0.003561917 \\
$10 \%$ & $10 \%$ & $80 \%$ & 0.001182764 & 0.000445208 & 0.006893969 \\
$15 \%$ & $10 \%$ & $75 \%$ & 0.001497374 & 0.000667654 & 0.010226020 \\
$15 \%$ & $15 \%$ & $70 \%$ & 0.001614438 & 0.000667810 & 0.010311307 \\
$15 \%$ & $20 \%$ & $65 \%$ & 0.001731501 & 0.000667965 & 0.010396594 \\
$20 \%$ & $20 \%$ & $60 \%$ & 0.002046111 & 0.000890412 & 0.013728646 \\
$20 \%$ & $25 \%$ & $55 \%$ & 0.002163175 & 0.000890568 & 0.013813933 \\
$25 \%$ & $25 \%$ & $50 \%$ & 0.002477785 & 0.001113014 & 0.017145984 \\
$25 \%$ & $30 \%$ & $45 \%$ & 0.002594848 & 0.001113170 & 0.017231271 \\
$25 \%$ & $35 \%$ & $40 \%$ & 0.002711912 & 0.001113325 & 0.017316558 \\
$25 \%$ & $40 \%$ & $35 \%$ & 0.002828975 & 0.001113481 & 0.017401845 \\
\hline
\end{tabular}

Data sources: Oriental wealth network, the website of People's Bank of China

Once the target yields are determined, then the proportions of the portfolio calculated according to the Markowitz portfolio theory can keep the risk smallest. From table 5, while investing in stock share, the greater the average monthly income, the greater variance it has, namely, the greater risk it has been through. Therefore, adjusting the investment share can change benefits, and it can also adjust the risk. When the risk is under control, we can adjust investment share to keep the expected yield.

\section{Summary}

In view of the present crisis, we discuss pension fund operation mechanism and evaluate and explore the pension fund investment operation. For the contemporary study of pension fund. We use the theory of portfolio, take CPI, the urban residents disposable income growth rate, GDP as the target rate and calculate the matching portfolio proportion. Also, we explored three investment strategies, calculate their matching portfolio and analyze the risk conditions. Pension fund need to be reformed, which needs the encourage of national policy, the perfection of market mechanism, relaxation of investment mode, etc. Only by the scientific and effective investment, can we truly realize the value of pension fund, and promote social harmony and orderly development.

\section{References}

[1] Cao Chun. Reform of the social security fund-raising mechanism research [D]. The ministry of finance financial science institute, 2012.

[2] David•Neumark,Joanne•Song. Do stronger age discrimination laws make Social Security reforms more effective?[J].Journal of Public Economics.2013

[3] Alisdair•McKay. Search for financial returns and social security privatization [J].Review of Economic Dynamics.2013 (2)

[4] Xiang Huaicheng. A few questions about the national social security fund [J]. Journal of Central University of Finance and Economics, 2006(1).1.

[5] Li Yong. The literature review of national social security fund investment research [J]. Explore the economic problems, 2012(9).

[6] Tang Dapeng,Zhai Luping. Can investment portfolio reduce the investment risk of China's social security fund? [J]. Economic management, 2014(3):169-179. 
[7] Gu Mingshu,Liu Chang. Endowment insurance fund investment portfolio strategy research in China [J]. Journal of monetary economics, 2013(7):57-64.

[8] China's pension net. The revelution about China's social security fund based on the marketization [EB/OL].[2012-01-17].http://www.cnpension.net.

[9] Wang Bo. The capital asset pricing theory research based on investor sentiment [J]. Explore the economic problems, 2014(3):150-154.

[10]Harry M Markowitz. Portfolio Selection[J].Journal of Finance.1952(1) 